\title{
Construction of Gymnastics Performance Evaluation Model Based on Multiple Intelligence Theory
}

\author{
Xiangle Meng \\ Physical Education College \\ Yan'an University \\ Yan'an, China \\ Email:mz7006@126.com
}

\begin{abstract}
By using the method of literature, logical analysis, the study reviewed the connotation of the multiple intelligences theory, analyzed the inspirations brought by the theory to gymnastics performance evaluation, expounded the necessity of the reform of gymnastics performance evaluation model, and finally put forward the construction of a new evaluation model on gymnastics performance. The results show that a reasonable evaluation model of gymnastics performance, based on the multiple intelligence theory, should include subjects, methods, goals, principles and contents. At the same time, the model should be scientific and comprehensive. Ii is concluded that the new model will be more suitable for evaluating student's gymnastics performance.
\end{abstract}

Keywords-evaluation model; performance; gymnastics; multiple intelligence theory

\section{INTRODUCTION}

Since 1990s, the multiple intelligences evaluation theory was applied practically and widely in performance evaluation of primary and secondary school students in many countries and regions in the world, especially in the United States, Japan and Taiwan and other places. However, scholars in China do less related researches, and the achievements are not abundant. From the whole point of view, more qualitative researches have been done, mainly through theoretical discussion, explore "what kind of evaluation model is more reasonable?", "how to build?", ,how to implement?", "how to operate?" Therefore, solving these problems, not only can make the evaluation of the role of teaching feedback, but also can encourage students to put them into other courses' study confidently.

\section{THE CONNOTATION OF MULTIPLE INTELLIGENCE THEORY AND ITS INSPIRATION}

In $80 \mathrm{~s}$, American scholar Gardiner put forward the multiple intelligence theory for the first time, and it has produced great repercussions in the academic circle, still has put forward a great challenge to the traditional intelligence. After the improvement of Gardiner and related personnel, a more perfect theoretical system was formed. Gardiner defined multiple intelligences as the physiological and psychological potential of individual processing information in a cultural environment. [1]

The theory is that each individual has linguistic intelligence, mathematical intelligence, spatial intelligence, sports intelligence, musical intelligence, interpersonal intelligence, intrapersonal intelligence and natural intelligence eight kinds of intelligence and has strong intelligence and weak intelligence in the intelligence, but they are an indispensable part of a body of intelligence. At the same time, the theory emphasizes that these intelligences have relative independence and individual differences. [2]

Although the multiple intelligences theory does not produce direct teaching, it is significant to consider this fact when designing a teaching system. [1] As a result, in the assessment of the performance of gymnastics, the multiple intelligences theory will bring beneficial enlightenment. Gymnastics teaching is an extremely complex chain process, including many links. Among them, the evaluation of students' gymnastics performance is a key link, but also the students most concerned about one aspect. Fair and reasonable evaluation of students' gymnastics learning achievement can directly enhance students' learning interest and learning motivation. Therefore, the multiple intelligence theory will lay a foundation for the evaluation of gymnastics performance.

\section{THE NECESSITY OF THE REFORM OF GYMNASTICS PERFORMANCE EVALUATION MODEL}

Teaching experiences show that gymnastics performance evaluation model has made the students lose enthusiasm of learning, resulting in students' cognition deviation on gymnastics course, but also has caused some difficulties encountered in the process of teachers' performance appraisal process. Therefore, the existing gymnastics performance evaluation model needs to change, need to optimize. Specific reasons are as follows:

\section{A. The disadvantages of the traditional evaluation model of physical education class}

The performance evaluation of gymnastics has the common content of other physical education performance evaluation. The performance evaluation model of the 
traditional physical education class is that the teacher is the main body, and the performance of students in the final examination class is evaluated according to the established speed, quantity and distance etc. Obviously, this kind of examination method has obvious disadvantages: do not reflect the individual differences, pay more attention to the end of the examination and ignored the process of assessment, evaluation of the content is not comprehensive, and lack of scientific. [3]

\section{B. The characteristics of the gymnastics program need a reasonable evaluation model}

The evaluation method of the current performance of the gymnastics class is mainly based on the teacher centered evaluation. At the same time, because of the characteristics of the gymnastics and the uneven quality of students, performance evaluation is lack of rationality. First of all, the current evaluation method weakens the students' learning effect. Gymnastics has strict requirements on the practitioners, that is, the requirements of the practitioners cannot be too high and not too heavy, both physical symmetry and the relative strength of a strong, both to be flexible and can effectively control the body. Therefore, for students who cannot meet the requirements of the above, gymnastics is their weak project. Although try their best to practice, the final assessment content is like a mountain blocking the way they go, so that students lose confidence in learning, and hate gymnastics class. Teaching practices indicate that those students who fail the exam, participate in the make-up exam are likely to be the best student in some other courses. However, because of poor performance, gymnastics examine failed, appraised awards have been affected, even cannot graduate normally. Secondly, the gymnastics is relatively more professional. [4] Unlike basketball, football and other sports which students can participate in regardless of physical quality, actions in gymnastics like swivel, inverted, loop have higher requirements of students' comprehensive quality, resulting in poor basis of gymnastics. At the same time, the gymnastics course in the university is set up in the first year, so, those students who have no basis of gymnastics cannot meet the study speed and desired goals. Finally, some students find it difficult to learn gymnastics, and their enthusiasms of the course are seriously hurt.

\section{The teaching concept of "people-oriented" and "comprehensive development" call for humanistic and scientific evaluation methods}

"People-oriented" requires the evaluation can be objective, impartial, and scientific, can review of all aspects of the students, the way of evaluation and content can fit the actual situation of students, can reflect the whole picture of the students. [5] "Comprehensive development" is the core of quality education, so the evaluation of students is not only limited to one or some aspects, ignoring other aspects of collaborative development. Otherwise, it cannot effectively reflect the overall performance of individual differences. Therefore, the evaluation of students' gymnastics performance cannot be limited to sports intelligence, but also should include other aspects closely linked with the physical education study.
In a word, there are many drawbacks in evaluation of gymnastics performance's subject, content and method. Therefore, on the basis of the original, to establish a more reasonable evaluation mode is imperative. After a review, the multiple intelligence theory put forward by Gardiner just can provide us with a more reasonable research perspective.

\section{THE THEORETICAL CONSTRUCTION OF GYMNASTICS PERFORMANCE EVALUATION MODEL}

\section{A. The principles of gymnastics performance evaluation}

Based on the multiple intelligences theory, the evaluation of gymnastics performance needs to follow the principles of reasonable, scientific and comprehensive. In my opinion, the reasonable is mainly reflected in the content and the method of the evaluation that whether can truly reflect the students' learning results or not. The scientific refers to whether the evaluation of the content is reasonable or not, whether the proportion of each part is appropriate or not; whether the evaluation of the subject is objective, fair or not. The comprehensive refers to the target, the main subject and the method of the evaluation is comprehensive, whether it can fully reflect the students in the course of study of the whole performance or not. Therefore, only under the premise of rational, comprehensive and scientific, can it construct a more effective evaluation model.

\section{B. The targets of gymnastics performance evaluation}

The "Gymnastics Course Teaching Guidelines" issued by General Office of the Ministry of Education clearly points out that the current gymnastics course teaching is not only to the "student-centered", but also to cultivate and enhance students' practical application, moving mouth, practical ability in the course objectives and contents.

The construction of the gymnastics performance evaluation goals needs to be developed from the study goals and the requests of the gymnastics course. The overall goals of the course are to make students master basic theoretical knowledge, basic skills and basic abilities of gymnastics course, has the ability to engage in teaching and organizing activities in school physical education. The specific teaching objectives are as follows. First, the theoretical knowledge. To enable the students understand the characteristics and development situation of the gymnastics, and mainly master the theoretical knowledge terms, assistance and protection, queue formation, teaching organization and implementation methods, lay the theoretical foundation for the teaching practice scientifically and initiatively. Second, the basic skills. To enable students can independently accomplish the basic gymnastics with equipment, free hand gymnastics, queue formation and other projects, and still can achieve the standard of PE teachers teaching demonstration. Third, the basic teaching abilities. To enable students have the ability of organization and teaching, the ability to guide the mass fitness with gymnastic equipment. Therefore, the goal of gymnastics performance evaluation should start from the above three aspects. 


\section{The main subjects of gymnastics performance evaluation}

Gymnastics has the characteristic of "beauty", but the standard of beauty is different from person to person. Therefore, the evaluation of gymnastics performance often has a strong subjectivity. In order to minimize the deviation of the performance evaluation of gymnastics, based on the multiple intelligences theory, increasing the evaluation subject will be a necessary way. Therefore, three kinds of people should be included at least, including teachers, students-self and the other students. Teachers who carry out teaching have a longterm observation on students' classroom performance, having dynamic cognitions; the other teachers who participate in the examination have more relative objective evaluation results; students' self-evaluation is often more profound, and the other students' evaluation will be reference. So, the comprehensive evaluation of the three main subjects will make the gymnastics performance evaluation more reasonable.

\section{The methods of the gymnastics performance evaluation}

In my opinion, the evaluation methods of gymnastics performance are combined with process evaluation and final evaluation, and still with the combination of other evaluation and self evaluation. The process evaluation is reflected in the course of the study period which was dived with weeks. The final evaluation is mainly reflected in the final examination. Evaluation of others mainly includes teachers and the other students. Finally, the students' process evaluation score is the average of the two evaluation subjects' score. Self evaluation is mainly reflected in the students give themselves judgments. So, each student is required to make a record of his own performance and to make an assessment of the record at the end of the term.

Therefore, through such a method can make the evaluation more objective, more real, and more comprehensive.

\section{E. The contents of gymnastics performance evaluation}

Based on the multiple intelligence theory, the content of gymnastics performance evaluation should include eight aspects. However, each course has its unique contents evaluation, so, the specific content of the evaluation needs to be based on the specific characteristics and requirements of the course. From needs of the gymnastics study for student intelligence requirements, first of all, sports intelligence is the most important content. Secondly, space intelligence and verbal intelligence are the secondary contents. Finally, intrapersonal intelligence and interpersonal intelligence is the third content. Because music intelligence, natural intelligence and mathematical intelligence in gymnastics learning play a weak role, therefore, the three kinds of contents are not within the scope of the gymnastics evaluation contents.

For sports intelligence, the core content is whether students can grasp of gymnastics skills and abilities rapidly and accurately or not. In the course of teaching, some students' learning speed is faster than other students, and the learning quality is also higher. Students of this kind often become the top students in gymnastics learning process. They are often praised by teachers, and are appointed as teacher's teaching assistants. Other students with slower pace of learning, learning quality are not high, and this kind of student is the main object of teacher's teaching.

For space intelligence, the core content is whether students can perceive their own movement's status, body posture, as well as their relative position relationship between themselves and the device in space clearly. Spatial sense is one of the more important factors that determine the learning speed and quality. In the learning process, many students cannot identify their own body posture, resulting in the movement of deformation, lack of beauty. In terms of expression intelligence, it is mainly reflected in the students' ability to express the key points, difficulties, methods and matters needing attention of skills. So, students who can only do the action but cannot express will become "dumb man".

For intelligent introspection, the core content of is whether can make a reasonable summary of their performance or not, which can or cannot make a profound reflection on the advantages and disadvantages of their own, whether can put forward the future study direction or not. Many students have no habits to sum up and reflect after gymnastics class, to understand what they need to improve in the future, so they will still make the same mistakes in the next time, and then the learning effect is always poor. Interpersonal intelligence is mainly reflected whether can communicate with others actively in the learning process or not, whether can understand their own learning situation or not, whether will be like to enhance understanding or not etc. In the reality of learning, a small number of students are not good at communicating with others, are not willing to learn from others, and therefore cannot get more feedback which is good for making a progress.

\section{SUMMARY}

Based on the multiple intelligences theory, this paper probed into the optimization and construction of the gymnastics performance evaluation model. Because the reasonable evaluation of gymnastics performance can combine with the student's concerning, the study has a great practical significance. Although the study is only from theoretical perspective to explore the construction of the new model and its operability is not strong; and the study is still play a demonstrative and leading role.

\section{REFERENCES}

[1] Lei Guo. Preliminary conception of badminton teaching in the view of multiple intelligence theory $[\mathrm{J}]$. Hubei Sports Science and Technology, 2013, 32(4): 317+325-326.

[2] Xiang Li. Research on evaluation of college physical performance based on the multiple intelligence theory [J]. Sports Research and Education, 2013, 28(6): 55-57.

[3] Qiangjun Zhao. The construction of multiple intelligence evaluation system in physical education [J].Sports, 2016(7): 81-82.

[4] Yimin Yuan. Jiangsu province middle school gymnastics teaching present situation and countermeasure analysis $[\mathrm{J}]$. Journal of Beijing Sport University, 2009, 30(2):91-94.

[5] Ling Wang. The embodiment of the "people-oriented" teaching concept in university teaching $[\mathrm{J}]$. Journal of the Chinese Society of Education, 2015(1):325-326. 